\title{
TIME-FREQUENCY ANALYSIS OF 3D SHIP-WAVE FIELDS IN MARTIME WATERWAYS
}

\author{
Markus Brühl, Leichtweiß-Institute for Hydraulic Engineering and Water Resources, Technische Universität Braunschweig, \\ Germany, m.bruehl@tu-braunschweig.de \\ Rahi A. Shet, Institute of Communications Technology, Leibniz Universität Hannover, Germany
}

\section{INTRODUCTION}

In the last 15 years an increased number of serious damages of protective structures such as groins and revetments have been observed in maritime waterways. The analyses of these damages have shown that the current design approaches for the rubble mound layers of such structures are not sufficient to ensure sufficient stability against ship-induced wave loads. Since these approaches are determined for wind-induced waves, they do not consider the long-period ship-wave components. Within a joint research project, the design loads of shipinduced long-period waves on rubble mound structures in maritime waterways are investigated. By means of first project results, the knowledge gaps with respect to the classification and parameterization of ship waves have been identified. The project has clearly shown the need for a 3D analysis of three-dimensional, nonlinear shipwave fields. Therefore, another research project was initiated in order to generate the scientific knowledge for the parameterization of ship-induced 3D wave fields as required for the hydraulic design of rubble mound structures in maritime waterways with a special focus on the spatial and nonlinear properties of ship waves.

\section{WORK PROGRAMME AND METHODOLOGY}

The key research issues are (i) the numerical implementation of a nonlinear Fourier transform (Brühl, 2014) for the nonlinear frequency-domain analysis of three-dimensional ship wake fields (3D-NLFT) (Osborne, 2010), (ii) the numerical implementation of the HilbertHuang transform for the nonlinear time-frequencydomain analysis of three-dimensional ship wake fields (3D-HHT) (Wu \& Huang, 2009), (iii) a comparative analysis of ship-wave data using the implemented analysis methods (3D-NLFT and 3D-HHT) as well as conventional FFT and (iv) the parameterization of $3 D$ ship-wave fields in order to determine the relevant hydraulic design parameters for protective rubble mound structures in maritime waterways.

\section{PROSPECTIVE RESULTS OF THE PROJECT}

Within the project, recommendations will be developed for the selection of appropriate methods for the determination of wave parameters as well as for the selection of appropriate wave parameters that have been determined within this project. In the literature, definitions of the relevant wave parameters are available for 2D ship waves that will be extended and specified more precisely within this project. For 3D ship waves no data are available how to parametrize the ship waves. So for these $3 \mathrm{D}$ waves we have to determine which parameters and values from 2D ship waves are representative (Wöffler et al., 2014), and which parameters and values have to be determined additionally in order to accurately describe the 3D ship wave fields. For this, additional simulations and data analyses have to be performed. Finally, after the definition of the representative parameters, ship waves from laboratory tests, field measurements and numerical simulations will be characterized and classified based on these definitions. Within this procedure, the different problems and processes will be considered that are responsible for the interaction between ship-induced waves and protective measures in maritime waterways.

\section{TIME-FREQUENCY ANALYSIS OF 3D SHIP WAVES}

For the time-frequency analysis of ship-induced waves, the multi-dimensional ensemble empirical mode decomposition (MEEMD) is applied as introduced by Wu \& Huang (2009). The applicability of this method for the decomposition of long-period primary and short-period secondary waves with different angles of wave propagation has been shown by Shet (2017). In the next step, the applicability for the separation of secondary ship waves and wind-generated waves will be investigated. Actual results from the project and examples for the application of the MEEMD as time-frequency decomposition and analysis for 3D ship-wave fields will be presented at the conference.

\section{ACKNOWLEDGEMENTS}

The project „Parameterization of nonlinear ship-induced $3 D$ wave fields for the hydraulic design of protective structures in maritime waterways (PaNSiWa)" is funded by Deutsche Forschungsgemeinschaft (German Research Foundation, DFG BR 5289/2-1).

\section{REFERENCES}

Brühl, Markus (2014): Direct and inverse nonlinear Fourier transform based on the Korteweg-deVires equation (KdV-NLFT). A spectral analysis of nonlinear surface waves in shallow water. Dissertation. LeichtweißInstitut für Wasserbau, Technische Universität Braunschweig, Germany.

Osborne, Alfred R. (2010): Nonlinear ocean waves and the inverse scattering transform. 1. ed. Amsterdam: Academic Press (International geophysics series, 97).

Shet, R.A. (2017): Implementation and application of Hilbert-Huang transform for the analysis of threedimensional Wave Fields. Master Thesis. Indian Institute of Technology Roorkee, and TU Braunschweig, 63 pp.

Wöffler, T.; Brühl, M.; Uliczka, K.; Schüttrumpf, H. (2014): Small-scale investigations on the hydraulic stability of protective structures in maritime waterways (in German). HTG-Kongress 2014, 21.-23. Mai 2014, Berlin, Hafentechnische Gesellschaft (HTG), Berlin, S. 50-62.

Wu, Z.; Huang, N.E. (2009): The multi-dimensional ensemble empirical mode decomposition method. Advances in Adaptive Data Analysis, Vol. 1, No. 3, 339372. 